\title{
EXTRAÇÃO DO MATERIAL LIPÍDICO PRESENTE NA ESCUMA E NO LODO DE ESGOTO SANITÁRIO ATRAVÉS DE DIFERENTES MÉTODOS
}

\author{
H. S. BARROS ${ }^{1 *}$, L. V. SOUZA' ${ }^{1}$, A. P. B. SANTOS ${ }^{2}$, L. D. SOUZA ${ }^{1}$ e A. G. D. SANTOS ${ }^{1}$ \\ ${ }^{1}$ Universidade do Estado do Rio Grande do Norte - UERN \\ ${ }^{2}$ Universidade Federal do Rio Grande do Norte - UFRN \\ hilquiassabino@gmail.com*
}

Artigo submetido em junho/2014 e aceito em outubro/2015

DOI: 10.15628/holos.2015.2205

\section{RESUMO}

A reutilização do material lipídico (ML) presente nos esgotos apresenta-se como alternativa de matéria-prima para a produção de biodiesel. Seu uso para obtenção de energia alternativa, traz consigo, benefícios como: disponibilidade imediata, baixo custo e minimização de problemas ambientais. Porém, muitos desafios como a complexidade da matriz, a porcentagem de óleo e a falta de tecnologias prontas para a extração e esterificação deste material, acompanham a confirmação da sua viabilidade técnica e precisam ser resolvidos. Desta forma, este trabalho teve como objetivo analisar qual o método de extração é mais eficiente para obtenção do
ML da escuma e do lodo de esgoto, sendo estudados diferentes métodos de extração e diferentes tipos de solventes para a extração do óleo. Dentre esses métodos foi possível constatar que o método de Bligh\&Dyer (1959), foi o mais eficiente com rendimento de aproximadamente $6 \%$ de ML extraído da escuma. Porém, esse método é menos seletivo aos triglicerídeos que favoreceriam uma melhor conversão da matéria prima em biodiesel, indicando que deve considerar a boa porcentagem extraída dos outros métodos com o uso de hexano e ultrassom como potencialmente viáveis.

PALAVRAS-CHAVE: Biodiesel, Bligh \& Dyer, Estação de Tratamento de Esgoto.

\section{EXTRACTING THE LIPID MATERIAL PRESENT IN THE SCUM AND SANITARY SEWER SLUDGE THROUGH DIFFERENT METHODS}

\begin{abstract}
The reuse of this lipid material (LM) in the sewage is presented as an alternative raw material for biodiesel production. Its use for obtaining alternative energy, brings with benefits such as: imediate availability, low cost and minimizing environmental problems. But many challenges as the complexity of the matrix, the percentage of oil and the lack of ready technologies for the extraction and esterification of this material, follow the confirmation of their technical feasibility and need to be resolved. Thus, this study aimed to analyze which extraction method is more efficient to obtain the LM of
\end{abstract}

scum and sewage sludge, being studied different extraction methods and different types of solvents for oil extraction. Among these methods it was found that the method of Bligh \& Dyer (1959) was the most efficient yield of approximately $6 \%$ of LM extracted from the scum. However, this method is less selective to triglycerides that would favor a better conversion of raw material into biodiesel, which should consider good percentage extracted from other methods using hexane and ultrasound as potentially viable. 


\section{INTRODUÇÃO}

Dentre as matérias primas utilizadas para produção de biodiesel, a reutilização da gordura presente nos esgotos sanitários, têm sido objeto de recentes pesquisas sobre a importância da utilização de matérias primas alternativas para produção desse combustível (ROSENTHAL et al., 1996; MONDALA et al., 2008; BARROS et al., 2013; GIRISHA et al., 2014; POKOO-AIKINS et al., 2010). Por existirem poucos estudos sobre os processos que abordam a eficiência na recuperação deste material, há a necessidade de descobrir, estudar e implementar métodos de extração eficientes para essa matriz complexa.

Dentre as fontes existentes, o lodo de esgoto se apresenta com um potencial promissor de lipídios (BOOCOCK et al., 1992; JARDÉ et al., 2005; DUFRECHE et al., 2007; POKOO-AIKINS et al., 2010; OLIVEIRA, 2012; GIRISHA et al., 2014), sendo que a melhor forma de obtenção desse material é por meio da extração direta por solvente (RAMALHO \& SUAREZ, 2012). Dentre os métodos de extração mais utilizados independentemente da matriz, estão os por meio de solventes, onde duas fases estão em contato íntimo e o soluto pode se difundir de uma fase (sólida ou líquida), para outra fase líquida, resultando na separação dos compostos contidos, originalmente na mistura (GEANKOPLIS, 2003). O resultado desta reação é a obtenção do material lipídico (ácidos graxos), que posteriormente podem ser usados para a produção de biodiesel (BOOCOCK et al., 1992; POKOO-AIKINS et al., 2010; BARROS et al., 2013).

Alguns procedimentos para a extração de lipídios devem ser observados como: o prétratamento ou preparo da amostra (secagem, redução do tamanho da amostra ou hidrólise ácida); a homogeneização do tecido na presença de um solvente; separação das fases líquidas (orgânica e aquosa) e da fase sólida; a remoção dos contaminantes sólidos e de solvente e a secagem do extrato (SHAHIDI \& WANASUNDARA, 1998). A eficiência da extração depende do método empregado e para um mesmo método, deve-se observar o tipo de solvente ou a composição da mistura quando se utiliza mais de um solvente, além de outras condições que incluem fatores como: temperatura, tempo de agitação, utilização de acessórios/equipamentos, catalisadores da extração, dentre outros.

A utilização de material lipídico ( $\mathrm{ML}$ ) dos esgotos para produção de energia, traz vários benefícios, dentre eles a disponibilidade imediata, baixo custo, destino adequado ao descarte do resíduo produzido pelas estações de tratamento de esgoto (ETE) e contribuição com a redução da poluição, o que resulta em vários benefícios ambientais (POKOO-AIKINS et al., 2010; KALAM et al., 2011).

Assim, o objetivo desse trabalho foi avaliar o método de extração por solvente que seja mais eficiente na recuperação do ML presente na escuma e no lodo, gerado na estação de tratamento de esgoto sanitário do Baldo, na cidade de Natal-RN.

\section{METODOLOGIA}

Neste trabalho, o material analisado foi o da estação de tratamento de esgotos (ETE) do Baldo da cidade de Natal-RN, que tem capacidade de tratar aproximadamente 450 litros de esgoto por segundo (CAERN, 2013). Dados da literatura relatam que, para cada 200 litros de esgotos, existem em média 160 gramas de escuma, da qual 10\% é óleo/gordura (ECKENFELDER, 1970; JORDÃO \& PESSOA, 1995). Desta forma, estima-se que se obtenham aproximadamente três 
toneladas de gordura diariamente, proveniente do rejeito da ETE do Baldo, representando um alto ganho ambiental e econômico o aproveitamento desse rejeito para fins energéticos.

Devido os esgotos apresentarem como característica em sua composição aproximadamente $99 \%$ de líquidos (SHAHIDI \& WANASUNDARA, 1998), praticamente a mesma quantidade (99.3) encontrada nas amostras analisadas, foi necessário realizar a remoção da parte desse líquido nas amostras, tanto por meio de processos naturais (secagem ao ar livre), como por meio de equipamentos (estufas). A amostra da escuma, por ter sido colhida na parte superior dos tanques de decantação, continham grande quantidade de líquido, sendo necessária a pré-secagem em condições naturais, onde foram acomodadas em recipientes de 15 litros e expostas por aproximadamente 30 dias a uma temperatura de aproximadamente $35^{\circ} \mathrm{C}$, para que houvesse a evaporação da maior parte líquida da amostra, resultando na obtenção de uma pasta aquosa escura. A amostra do lodo secundário, por já apresentar essa característica pastosa, ocasionado pelo seu tratamento prévio feito na estação, não necessitou da pré-secagem realizada na amostra da escuma.

Após obter amostras do lodo e da escuma em seu estado pastoso, foi realizado o processo de desidratação dessas amostras, onde as mesmas foram acomodadas em um recipiente de vidro (bandeja), e colocadas na estufa a uma temperatura de $100^{\circ} \mathrm{C}$ até peso constante. O material seco foi homogeneizado em almofariz para se tornar um pó, o qual foi submetido à extração.

Os métodos de extração utilizados se diferenciavam pela técnica (a frio, centrífuga, ultrasson e Bligh \& Dyer(1959)), como também por diferentes solventes de padrão P.A (hexano, etanol e clorofórmio). Alguns dos procedimentos foram realizados com agitação manual (método a frio) e, também, com o uso de equipamentos como a centrifuga BIO ENG, modelo BE-4004 e o ultrasonic CLEANER 50, modelo 5040 DA. Ainda foi necessário a utilização de equipamentos complementares como a balança SHIMADZU, modelo AX 200, a estufa QUIMIS, modelo Q317m-52 e o analisador térmico marca Netzsch modelo STA 449 F3 Jupiter, além das vidrarias de laboratório como beckeres, provetas, pipetas, balão, etc. O procedimento detalhado de cada método é descrito a seguir.

\subsection{Método de extração a frio com hexano e etanol}

Foram pesadas 100 gramas da amostra em uma balança de precisão. Esta massa foi colocada em um becker de $500 \mathrm{~mL}$ e em seguida adicionou-se $300 \mathrm{~mL}$ de solvente (hexano ou etanol). Agitou-se manualmente por aproximadamente 5 minutos e deixou-se em repouso por 24 horas em temperatura ambiente. Após esse intervalo, a parte líquida composta por solvente e ML, foi removida por filtração em papel de filtro qualitativo para separação dos sólidos e em seguida, rotaevaporada para a remoção do solvente residual. Em seguida, foram expostas em estufa a uma temperatura de $65^{\circ} \mathrm{C}$, durante 24 horas, para eliminação da água e solvente residuais, obtendo apenas o ML.

O calculo da \% do material obtido por este e pelos outros métodos, foi realizado através da Equação 1.

$$
\% \mathrm{ML}=((\mathrm{M} 2 / \mathrm{M} 1) \times 100)
$$

Eq. 1.

Onde: M2 é massa do material lipídico (ML) extraído e M1 é a massa das amostras submetidas à extração. 


\subsection{Método de extração Bligh\&Dyer (1959)}

Para este método seguiu-se o mesmo procedimento descrito em trabalhos anteriores (IVERSON et al., 2001; BRUM, 2004), utilizando o etanol no lugar do metanol, em função de este ser menos tóxico, estrategicamente e ambientalmente mais interessante para o Brasil, por ser renovável e com tecnologia de produção consolidada.

\subsection{Método de extração com hexano e auxílio da centrífuga}

Neste método, o processo de preparo é semelhante ao método de extração a frio com hexano, diferenciando-se apenas na quantidade da massa empregada devido às limitações do centrifugador. Foram usadas 10 gramas da amostra e adicionado $30 \mathrm{~mL}$ de solvente (hexano) em seguida deixou-se sob agitação mecânica por 20 minutos. Após esse tempo o material ficou em repouso por 5 minutos e em seguida foi agitado por mais 5 minutos. Logo após, acondicionou-se a amostra em um tubo de ensaio apropriado e centrifugou-se por 5 minutos a uma rotação de 1300 rpm.

No processo da centrifugação, removeu-se a parte líquida da amostra e com um rotaevaporador, o solvente contido na amostra foi removido e em seguida, as amostras foram expostas em estufa a uma temperatura de $65^{\circ} \mathrm{C}$, durante 24 horas, para eliminação da água e solvente residuais, obtendo-se apenas o ML.

\subsection{Método de extração com auxílio de banho de ultrassom}

Este método seguiu o mesmo procedimento descrito por Freitas (2007), onde o equipamento empregado foi um Ultrasonic Cleaner, o qual foi montado numa estrutura composta por uma haste fixada a um suporte universal para adaptação do erlenmeyer de $250 \mathrm{~mL}$, como ilustrado na Figura 1.

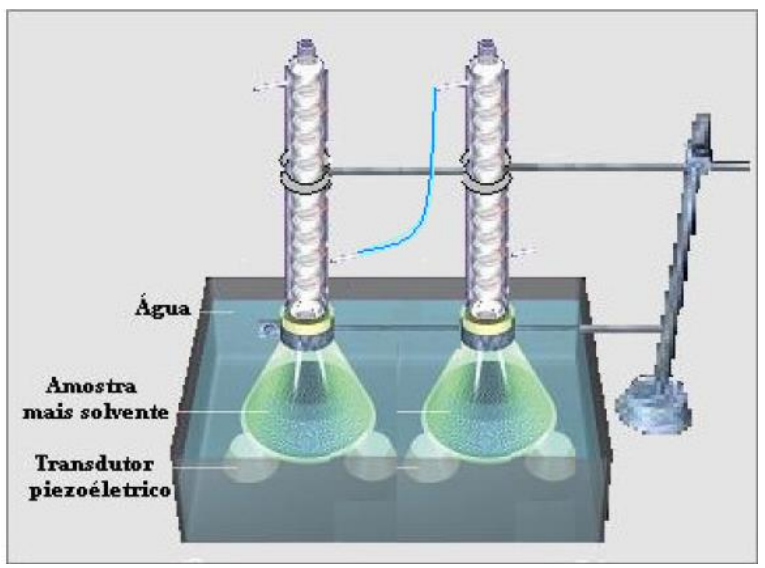

Figura 1. Esquema do ultrassom utilizado para a extração do ML de esgoto.

Fonte: Freitas (2007).

No erlenmeyer, colocou-se $3 \mathrm{~g}$ da amostra acrescida de $100 \mathrm{ml}$ de hexano e submeteu a mistura ao ultrassom por 120 minutos. Posteriormente, removeu-se o solvente e em seguida, as amostras foram transferidas para estufa, a uma temperatura de $65^{\circ} \mathrm{C}$, durante 24 horas, para eliminar a água e solvente residuais, obtendo apenas o ML.

Todas as extrações foram realizadas em triplicatas no Laboratório de Catálise, Ambiente e Materiais (LACAM) com os resultados sendo a média aritmética delas. 


\section{RESULTADOS E DISCUSSÕES}

Após a etapa de extração, os resultados obtidos para a escuma e para o lodo, nas diferentes condições (úmida e seca) e com os cinco (5) diferentes métodos são apresentados na tabela 1. Eles revelaram que a porcentagem de ML na escuma, foram superiores ao do lodo, sendo que o método de Blig \& Dyer (1959), foi o que apresentou os melhores resultados.

Tabela 1: ML extraído na escuma e no lodo do esgoto sanitário através dos diferentes métodos avaliados.

\begin{tabular}{c|c|c|c|c|c|c}
\hline \multirow{2}{*}{ Amostra } & & Hexano & Etanol & Bligh\&Dyer (1959) & $\begin{array}{c}\text { Hexano e } \\
\text { centrífuga }\end{array}$ & $\begin{array}{c}\text { Hexano e } \\
\text { Ultrassom }\end{array}$ \\
\hline \multirow{2}{*}{ Úmida (\%) } & Escuma & 0,39 & 1,31 & 0,98 & 0,23 & *SE \\
\cline { 2 - 7 } & Lodo & 0,06 & 0,18 & 1,15 & $S^{*}$ & 0,02 \\
\hline \multirow{2}{*}{ Seco (\%) } & Escuma & $S E^{*}$ & 4,26 & 5,94 & 2,83 & 5,02 \\
\cline { 2 - 7 } & Lodo & $S E^{*}$ & 1,73 & 4,95 & 0,50 & 3,44 \\
\hline
\end{tabular}

*SE= sem extração

Os resultados mostram que a presença de água nas amostras úmidas resulta em uma porcentagem de extração menor, já que a massa de produto inicial (M1) usada no cálculo, tem incluída a água que é eliminada no processo durante a purificação. Assim o processo de extração das amostras secas resulta em porcentagens maiores de extração. No entanto, é bom destacar que na extração úmida, é eliminada uma etapa do procedimento e isso pode ser mais interessante economicamente.

Não foi possível realizar o procedimento de extração utilizando o hexano como solvente na amostra seca, visto que, à quantidade de material desidratado usado, absorveu todo o solvente (utilizado na proporção de $3: 1 \mathrm{~m} / \mathrm{m}$ ). Desta forma, a proporção de solvente utilizado, não foi suficiente para diluir a amostra, o que indica a necessidade do uso de maior quantidade de solvente para a sua extração.

Este procedimento não foi realizado neste trabalho em virtude de estarmos interessados em comparar os resultados das amostras úmidas e secas e assim, a mudança nas quantidades poderia alterar a eficiência do método e os resultados obtidos.

Para o caso da escuma úmida, o uso auxiliar da centrifuga diminui o rendimento de extração praticamente pela metade, quando comparado ao método utilizando apenas o hexano.

Já com o uso do ultrassom, não foi possível obter nenhum ML devido não ter ocorrido à interação da amostra e solvente durante o processo de extração. O baixo rendimento pode ser consequência da baixa quantidade de amostra inicial que se tem que usar nos métodos com auxilio de aparelhos, o que requer o uso equipamentos que permitam fazer a extração de uma quantidade maior de material ou equipamentos de maior sensibilidade para calcular a quantidade de óleo extraído.

A utilização do ultrassom para a extração do $\mathrm{ML}$, mostrou resultados semelhantes à literatura (LI et al., 2004), alcançando valores maiores quando comparado com outros métodos que utilizaram solventes apolares. Dessa forma, o emprego dessa técnica é bastante eficaz para reduzir gastos no processo de extração, já que utilizando solvente de menor custo é mais eficiente na extração de ML, conforme descrito na literatura (KARGBO, 2010).

Os resultados obtidos na extração do $\mathrm{ML}$ da escuma mostram que existe uma grande 
quantidade de material polar que só é extraída quando se usa solvente polar (álcool ou clorofórmio + água e o método de Bligh \& Dyer (1959).

Fica evidente também, que os métodos com solventes polares são mais eficientes na extração que os com solventes apolares (hexano), sendo que o etanol é mais eficiente na extração das amostras úmidas e a mistura de solventes, é mais eficiente na extração do material seco.

Outra opção para se obter ML dos rejeitos em uma estação de tratamento de esgoto e que pode aumentar o fornecimento de matéria prima, são os lodos originários do processamento secundário do tratamento. Os resultados mostram percentuais de extração de ML inferiores aos encontrados na escuma de esgoto, mas indica que o lodo de esgoto, também, pode ser uma alternativa viável para a obtenção de matéria prima para produção do biodiesel. Novamente, o etanol é mais eficiente que o hexano e o método de Bligh \& Dyer (1959), é o mais eficiente de todos com aproximadamente $5 \%$ de material extraído.

Esses resultados são menores, embora próximos aos citados na literatura (KARGBO, 2010), que indica $7 \%$ de ML no lodo de esgoto, com a diferença podendo ser atribuída as próprias diferenças dos esgotos utilizados em função de sua origem.

Os percentuais extraídos, nos diversos métodos, mostram o mesmo comportamento obtido na escuma, indicando que a fração de lodo também é formada por uma mistura de materiais polares e apolares, embora neste caso, a concentração de materiais polares seja menor (aproximadamente 30\%).

A partir dos dados das Tabelas 1 e 2, foi plotada a Figura 2 com todos os resultados obtidos. Nela pode-se facilmente visualizar e comparar a eficiência de cada método em relação aos demais, deixando claro que o método Bligh \& Dyer (1959), é o mais eficiente em todos os casos, exceto na extração da escuma úmida.

Pode-se observar também, que o método usando ultrassom atinge um percentual significativo de extração, considerando que estão sendo extraídos apenas os compostos apolares presentes na mistura.

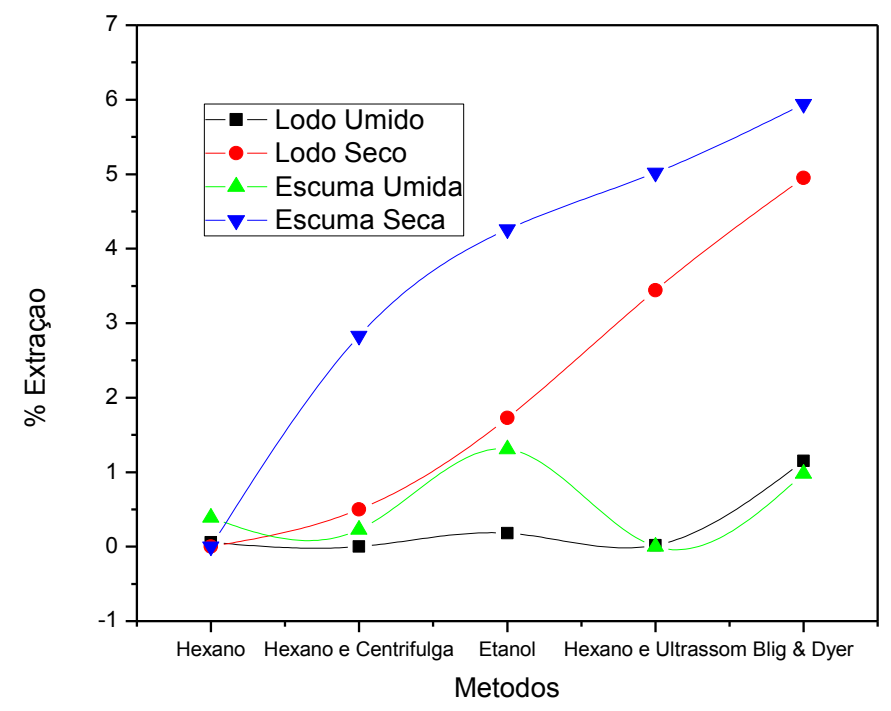

Figura 2. ML extraído da escuma (úmida e seca) e do lodo (úmido e seco) através dos diferentes métodos avaliados. 
O método utilizando à centrífuga, apesar de possuir uma menor eficiência possui a vantagem de extrair um ML visualmente mais limpo e de menor viscosidade. Já o material extraído com o método de Bligh \& Dyer (1959), é visualmente, bem mais viscoso, sendo parecido com uma graxa em temperatura ambiente como ilustrado na Figura 3.

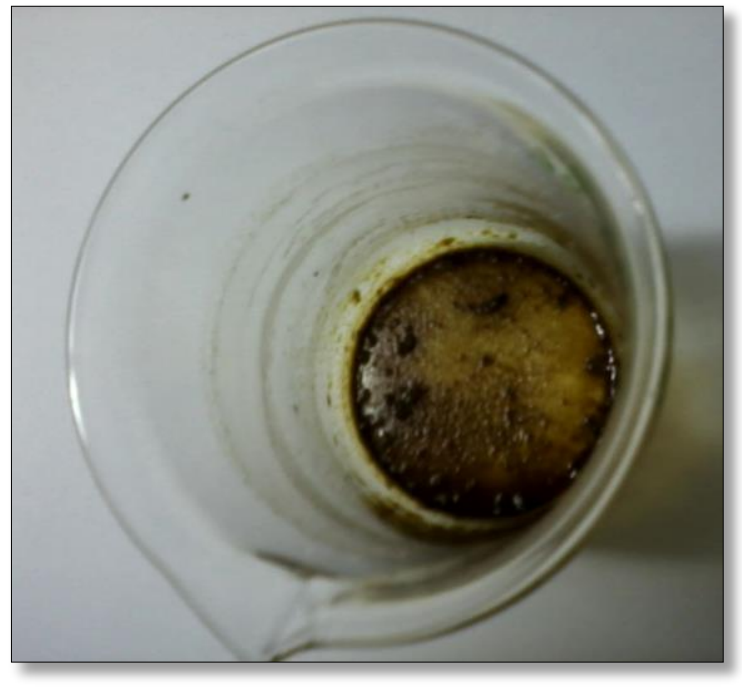

Figura 3. ML extraído do resíduo da ETE do Baldo com o método de Bligh \& Dyer (1959).

O material extraído com etanol, também apresentou uma alta viscosidade, o que provavelmente deve ser devido a sua polaridade que permite a extração de compostos polares presentes no esgoto e possivelmente, indesejáveis para a produção de biodiesel.

Deve-se ressaltar que, como se visa à produção de biodiesel o método usando o hexano e ultrassom, apresentou resultados semelhantes ao método de Blig \&Dyer (1959) com as amostras secas, o qual é significante já que teoricamente, ele é o que extrai em maior quantidade os ácidos graxos que irão ser convertidos em biodiesel.

Com respeito ao $\mathrm{ML}$ do lodo, foi constatado que a sua quantidade é de aproximadamente a metade do encontrado na escuma, indicando que este material também é uma fonte viável, sendo que o mesmo apresenta a vantagem adicional de já ter grande parte da água eliminada na própria ETE, o que torna processo de extração mais rápido e barato por não necessitar da etapa de pré-secagem feita na escuma.

\section{CONCLUSÃO}

Em conformidade com os resultados apresentados, concluem-se que:

- A quantidade de óleo extraído suas características visualmente observáveis (cor e viscosidade) dependem do método de extração e do solvente utilizado.

- O método Bligh \& Dyer (1959), foi o mais eficiente, extraindo aproximadamente $6 \%$ de óleo da escuma seca.

- Apesar de possuir uma quantidade menor de óleo, o lodo pode ser utilizado como alternativa para a extração de ML para produção de biodiesel, tendo a vantagem de apresentar menos água, o que reduz os custos e o trabalho de extração. 
- Mesmo tendo apresentado rendimentos inferiores aos outros métodos, a extração com hexano e ultrassom deve ser considerada com cuidado, pois, provavelmente, é a que produz ML com maior quantidade de compostos esterificáveis.

- O método que utiliza a centrífuga é outro que, também, merece ser considerado, visto que apresentou o ML visualmente mais limpo e com menor viscosidade, característica muito importante e determinante na eficiência do futuro processo de síntese do biodiesel usando o material.

- São necessários estudos para caracterização do ML extraído e confirmação do melhor método a se utilizar, bem como, avaliar a viabilidade de seu uso na síntese de biodiesel.

\section{REFERÊNCIAS}

1. BARROS, H.S. ; MAIA, C.E.M. ; SOUZA, L.D. Extração do óleo presente na escuma de esgoto para uso na produção de biodiesel. Química: Ciência, Tecnologia e Sociedade, v. 2, n. 1, p. 4248. 2013.

2. BLIGH, E.G.; DYER, W.J. A rapid method of total lipid extraction and purification. Canadian Journal of Biochemistry and Physiology, v.37, n.8, p.911-917, 1959.

3. BOOCOCK, D.G.B. et al. Fuels and chemicals from sewage sludge: 1 . The solvent extraction and composition of a lipid from a raw sewage sludge. Fuel, v.71, n. 11, p.1283-1289, 1992.

4. BRUM, A. A. S. Métodos de extração e qualidade da fração lipídica. 2004. 66f. Dissertação (Mestrado em Ciências). Escola Superior de Agricultura Luiz de Queiroz, Universidade de São Paulo - ESALQ/USP. Piracicaba.

5. Companhia de Águas e Esgoto do Rio Grande do Norte-CAERN. Disponível em:<http://http://www.caern.rn.gov.br. Acessado em: 28 out. 2013.

6. DUFRECHE, S. et al. Extraction of lipids from municipal wastewater plant microorganisms for production of biodiesel. Journal of the American Oil Chemists' Society, 84, p. 181-187, 2007.

7. ECKENFELDER, Jr.W.W. Water quality engineering for practicing engineers. Inc. New York: Barnes \& Noble, p. 341, 1970.

8. FREITAS, L.S. Desenvolvimento de procedimentos de extração do óleo de sementes de uva e caracterização química dos compostos extraídos. 2007. 227f. Tese (Doutorado em Química). Universidade Federal do Rio Grande do Sul - UFRGS. Porto Alegre.

9. GEANKOPLIS, C.J. Transport processes and separations process principles. 4a ed., Prentice Hall, 2003, p.754.

10. GIRISHA, S.T. et al. Lipid extraction for biodiesel production from municipal sewage water sludge. European Journal of Experimntal Biology, v. 4, n. 1 p. 242-249, 2014.

11. IVERSON, S.J; LANG, S.L.C.; COOPER, M.H. Comparison of the bligh and dyer and folch methods for total lipid determination in a broad range of Marine tissue. In Lipids, v. 36, $n$. 11, p. 1283-1287, 2001.

12. JARDÉ, E.; MANSUY, L.; FAURE, P. Organic markers in the lipidic fraction of sewage sludges. Water Research, v. 39, p. 1215-1232, 2005.

13. JORDÃO, E.P.; PESSOA, C.A. Tratamento de esgotos domésticos. $3^{a}$ Ed., Rio de Janeiro, ABES, 
1995.

14. KALAM, M.A. et al. Emission and performance characteristics of na indirect ignition diesel engine fuelld with waste cooking oil. Energy, v. 1, p. 397-402, 2011.

15. KARGBO, D.M. Biodiesel production from municipal sewage sludges. Energy \& Fuels. V. 24. p. 2791-2794, 2010.

16. LI, H.; PORDESIMO, L.; WEISS, J. High intensity ultrasoun-assisted extraction of oil from soybeans. Food Research International. v. 37, p. 731-738. 2004.

17. MONDALA, A. et al. Biodiesel prodction by in situ transesterication of municipal primary and secondary sludges. Bioresource Technology, v.100, p. 1203-1210, 2008.

18. OLIVEIRA, J.P. Estudo da geração de biodiesel a partir de resíduos oleosos do saneamento ambiental. 2012. 91 f. Dissertação (Mestrado em Engenharia Ambiental). Universidade Federal do Espírito Santo, Vitória. 2012.

19. POKOO-AIKINS, G. et al. A multi-criteria approach to screening alternatives for converting sewage sludge to biodiesel. Journal of Loss Prevention in the Process Industries, v.23, p. 412420, 2010.

20. RAMALHO, H.F. ; SUAREZ, P.A.Z. A química dos óleos e gorduras e seus processos de extração e refino. Revista Virtual de Química. v.5, n.1, p. 2-15, 2012.

21. ROSENTHAL, A.; PYLE, D.L.; NIRANJAN, K. Aqueous and enzymatic processes for edible oil extraction. Enzyme and Microbial Technology, v. 19, p. 402-420, 1996.

22. SHAHIDI, F.; WANASUNDARA, J.P.D. Extracion and analysis of lipids. In: AKOH, C.C; MIN, D.B. Food Lipids: chemistry, nutrition and biotechnology. Cap. 5, p. 115-135, 1998. 